\title{
Perilaku makan dan kejadian obesitas anak di SD Negeri Kota Kendari, Sulawesi Tenggara
}

\author{
Eating behavior and incidence of childhood obesity in Elementary School of Kendari City, South- \\ East of Sulawesi
}

Supiati ${ }^{1}$, Djauhar Ismail'2, Retna Siwi $P^{3}$

\begin{abstract}
Background: Obesity is a health problem in developed countries as well as developing countries like Indonesia. National prevalence of overweight children aged $6-14$ years is $9.5 \%$ in male and $6.4 \%$ in female. In Sulawesi Tenggara, there are $6.2 \%$ of male and $4.5 \%$ of female children who were overweight. Obesity in City of Kendari, there was an increase of obesity prevalence $0.15 \%$ in 2007 and $0.26 \%$ in 2008 . Obesity can be influenced by various factors. It issuspected that eating behavior is a major factor, so we want to know, how big is the eating behaviors contribute to children's obesity

Objectives: To determine the relationship of eating behavior and incidence of childhood obesity in one favorite public elementary school in Kendari Sulawesi Tenggara Province

Methods: This research was observational with cross sectional study design it was conducted in May 2010. Data was analysed using comparative test (chi square), and logistic regression

Results: There was significant correlation between eating behavior and obese incidence $(p<0.01)$ with the power of prevalence ration $(P R)$ was protective in their nature $(P R=1 / 0.12=8.3$ In other words, the subject with healthy eating behavior had probability 8.3 times greater to not obese

Conclusions: There was significant correlation between diet behavior and the obesity in the children with the power of correlation and prevalence ratio was protective. The subject with healthy diet behavior had probability of 8.3 times to avoid obese incidence compared to the subject with non healthy eating behavior
\end{abstract}

KEYWORDS: eating behavior, obesity, elementary school children

\begin{abstract}
ABSTRAK
Latar belakang: Obesitas merupakan masalah kesehatan di negara maju dan berkembang seperti Indonesia. Prevalensi nasional berat badan lebih anak usia 6-14 tahun pada laki-laki 9,5\% dan pada perempuan 6,4\%. Di Sulawesi Tengggara, prevalensi tersebut 6,2\% pada laki-laki dan 4,5\% pada perempuan. Obesitas di Kota Kendari meningkat setiap tahun yaitu 0,15\% pada tahun 2007 dan 0,26\% tahun 2008. Obesitas dapat dipengaruhi oleh berbagai faktor, diduga perilaku makan merupakan faktor utama, sehingga ingin diketahui seberapa besar pengaruh perilaku makan menyumbang terhadap kejadian obesitas.

Tujuan: Untuk mengetahui hubungan antara perilaku makan dan kejadian obesitas anak di SDN favorit Kota Kendari Provinsi Sulawesi Tenggara

Metode: Jenis penelitian ini adalah penelitian observasional dengan rancangan penelitian cross- sectional yang dilaksanakan pada bulan Mei 2010. Analisis data menggunakan uji komparatif (chi square), dan regresi logistik

Hasil: Ada hubungan terbalik antara perilaku makan dengan obesitas anak. $P<0,01$ dengan kekuatan hubungan dan rasio prevalensi $(R P)=1 / 0,12=83$, yaitu subjek yang mempunyai perilaku makan sehat mempunyai peluang 8,3 kali lebih besar untuk terhindar dari terjdinya obesitas.
\end{abstract}

\footnotetext{
${ }_{1}^{1}$ Poltekkes Kemenkes Kendari, JI. Jend. A.H. Nasution. No. G.14 Anduonohu, Kota Kendari.

2 Bagian Tumbuh Kembang Anak, Rumah Sakit Umum Pusat Dr. Sardjito, JI. Kesehatan, Yogyakarta.

${ }^{3}$ Minat Kebijakan dan Manajemen Pelayanan Kesehatan Fakultas Kedokteran Universitas Gajah Mada,

JI. Farmako, Sekip Utara, Yogyakarta.
} 


\begin{abstract}
Kesimpulan: Ada hubungan yang sangat signifikan antara perilaku makan dengan obesitas anak, dengan kekuatan hubungan dan rasio prevalensi yang bersifat protektif yaitu subjek yang mempunyai perilaku makan sehat mempunyai peluang 8,3 kali untuk terhindar dari terjadinya obesitas dibandingkan dengan anak yang berperilaku makan tidak sehat.
\end{abstract}

KATA KUNCI: perilaku makan, obesitas, anak sekolah dasar

\section{PENDAHULUAN}

Di seluruh dunia saat ini, sekitar 1,6 miliar orang dewasa mengalami keadaan berat badan lebih (overweight) dan sekurang-kurangnya 400 juta di antaranya mengalami obesitas. Tahun 2015 diperkirakan 2,3 juta orang dewasa akan mengalami overweight dan 700 juta di antaranya obesitas (1).

Prevalensi nasional obesitas umum usia $\geq 15$ tahun sebesar $10,3 \%$. Obesitas tidak hanya terjadi pada orang dewasa bahkan terjadi pada anakanak umur 6-14 tahun (usia sekolah). Di Provinsi Sulawesi Tenggara, didapati prevalensi berat badan lebih pada kalangan anak usia 6-14 tahun sebesar $6,2 \%$ (laki-laki) dan 4,5\% (perempuan) (2).

Obesitas anak jelas menjadi masalah kesehatan serius bukan semata karena keberlanjutannya (30$60 \%$ ) menjadi obesitas dewasa (3), tetapi juga karena dampak negatif terhadap kesehatan yang ditimbulkan. Dampak negatif pada anak, antara lain bisa berupa hipertensi, penyulit ortopedi, dan gangguan psikologis yang kesemuanya berujung sebagai penurunan mutu kehidupan, di samping menambah beban ekonomi keluarga dan negara (4). Fenomena obesitas mendasari perlunya mengevaluasi obesitas sejak dini karena usia tersebut masih mudah diatasi dan usia dewasa semakin sulit dan perubahan status obesitas siswa-siswi remaja menjadi non obesitas sangat kecil (5).

Obesitas merupakan dampak ketidakseimbangan asupan yang jauh melampaui keluaran energi dalam jangka waktu tertentu (4). Hasil penelitian Pampang, menemukan bahwa anak yang obes cenderung mengonsumsi energi lebih tinggi 6,9 kali lebih besar dibanding anak yang tidak obes, kebiasaan bergaya-hidup sedentary karena kemanjaan akibat kemajuan teknologi telah mempercepat pertambahan kasus obesitas. Ketersediaan televisi telah dapat meningkatkan angka kejadian obesitas $(6,4)$.
Umumnya, perilaku makan anak sekolah masih dipengaruhi oleh kelompok ataupun orang tuanya dan sekolah dapat membentuk perilaku makan anak, karena di lingkungan sekolah anak mudah terpapar makanan jajanan kaki lima dan anak mempunyai kemampuan membeli disebabkan harganya yang murah, menarik, dan bervariasi (7). Menurut Devi, perilaku makan dan status gizi anak menunjukkan hubungan yang signifikan (8).

Perilaku makan merupakan kebiasaan makan yang bisa diubah dan diduga merupakan prediktor yang kuat bagi terjadinya obesitas. Selain itu, survei awal tahun 2009, mendapatkan angka obesitas di SDN 12 Baruga sebesar 76 orang $(8,6 \%)$. Menurut Wing (Soegih dan Wiramihardja), berat badan dipengaruhi perilaku makan sehingga ingin diketahui seberapa jauh peran perilaku makan tersebut dalam menyumbang terhadap kejadian obesitas (9).

\section{BAHAN DAN METODE}

Jenis penelitian ini adalah penelitian observasional dengan rancangan cross-sectional dilaksanakan pada Bulan Mei-Juli 2010. Penelitian dilaksanakan di Sekolah Dasar Negeri 12 Baruga (Kuncup Pertiwi). Alasan pemilihan sekolah ini karena merupakan sekolah favorit di Kota Kendari dan diduga prevalensi anak obes cukup tinggi. Populasi penelitian ini adalah seluruh anak SD yang berada di SD Kuncup Kota Kendari, murid kelas 2 sampai kelas 5 yang mengalami obesitas sebanyak 76 orang. Data tersebut diperoleh dari guru UKS (usaha kesehatan sekolah). Setelah dilakukan pengukuran, diperoleh 241 orang, kemudian Peneliti mempertimbangkan pemilihan subjek berdasarkan kriteria inklusi dan ekslusi maka diperoleh 83 orang. Data dianalisis secara univariat, bivariat dan dilanjutkan dengan multivariat pada tingkat kepercayaan $95 \%$. 
HASIL

\section{Karakteristik responden}

Terdapat 83 responden siswa Sekolah Dasar Negeri Kuncup Pertiwi (12 Baruga). Adapun karakteristik secara umum dapat dilihat pada Tabel 1.

Tabel 1 menunjukkan bahwa sebagian besar subjek berumur $\leq 10$ tahun, mempunyai status gizi obesitas ringan, mempunyai asupan energi melebihi $\%$ AKG kebutuhan, dan mempunyai orang tua dengan kategori obesitas yang mempunyai tingkat pendapatan keluarga yang tinggi.

\section{Hubungan perilaku makan dengan obesitas anak}

Tabel 2 menunjukkan terdapat hubungan yang signifikan antara perilaku makan dengan terjadinya obesitas $(p<0,01)$ dengan kekuatan hubungan rasio prevalensi yang bersifat protektif $(R P)=1 / 0,12=8,3$. Dengan kata lain, subjek yang mempunyai perilaku makan sehat mempunyai peluang 8,3 kali lebih besar untuk terhindar dari terjadinya obesitas.

Hubungan variabel luar (umur, jenis kelamin, asupan energi, genetik, sosial ekonomi) dengan obesitas

Tabel 3 menunjukkan tidak terdapat hubungan antara jenis kelamin, umur, asupan makanan di sekolah, status gizi bapak, dan tingkat pendapatan keluarga dengan obesitas pada subjek penelitian. Terdapat hubungan yang sangat signifikan antara total asupan energi (di rumah dan di sekolah) dengan terjadinya obesitas yang bersifat protektif $p<0,01$ dengan kekuatan hubungan $\mathrm{RP}=0 / 0,14=7,1$ kali. Anak yang mempunyai asupan energi sesuai kebutuhan tubuh (cukup) akan terhindar dari obesitas sebesar 7,1 kali lebih besar dibandingkan dengan anak yang mempunyai asupan energi lebih besar dari \% AKG.
Tabel 1. Karakteristik responden penelitian

\begin{tabular}{|c|c|c|}
\hline Variabel & $\mathbf{N}$ & $\%$ \\
\hline \multicolumn{3}{|l|}{ Umur (tahun) } \\
\hline$\leq 10$ & 59 & 71,1 \\
\hline$>10$ & 24 & 28,9 \\
\hline \multicolumn{3}{|l|}{ Jenis kelamin } \\
\hline Laki-laki & 47 & 56,6 \\
\hline Perempuan & 36 & 43,4 \\
\hline \multicolumn{3}{|c|}{ Perilaku makan anak } \\
\hline Sehat & 31 & 37,3 \\
\hline Tidak sehat & 52 & 62,7 \\
\hline \multicolumn{3}{|c|}{ Asupan energi di sekolah } \\
\hline$>50 \%$ AKG & 48 & 57,8 \\
\hline$<50 \%$ AKG & 35 & 42,2 \\
\hline \multicolumn{3}{|c|}{ Asupan energi total } \\
\hline$>100 \%$ AKG & 45 & 54,2 \\
\hline$<100 \%$ AKG & 38 & 45,8 \\
\hline \multicolumn{3}{|c|}{ Status gizi (IMT) bapak (+) } \\
\hline Obes & 52 & 62,7 \\
\hline Normal & 31 & 37,3 \\
\hline \multicolumn{3}{|c|}{ Status gizi (IMT) ibu (+) } \\
\hline Obes & 46 & 55,4 \\
\hline Normal & 37 & 44,6 \\
\hline \multicolumn{3}{|c|}{ Status gizi (IMT) ibu (++) } \\
\hline Obes & 26 & 31,3 \\
\hline Normal & 57 & 68,7 \\
\hline \multicolumn{3}{|c|}{ Pendapatan keluarga } \\
\hline Tinggi & 45 & 54,2 \\
\hline Cukup & 38 & 45,8 \\
\hline
\end{tabular}

Selanjutnya, diikuti oleh status gizi ibu ada hubungan yang signifikan antara status gizi ibu dengan obesitas $p<0,05 R P=3,4$. Demikian pula status gizi orang tua (ibu dan bapak), yaitu salah satu di antaranya atau keduanya obes akan mempunyai hubungan yang signifikan dengan obesitas pada anak

\section{Analisis multivariat hubungan beberapa variabel dengan obesitas}

Penelitian ini menggunakan analisis multivariat regresi logistik dengan metode backward. Hal tersebut dipilih untuk mengendalikan beberapa

Tabel 2. Hubungan antara perilaku makan dengan obesitas

\begin{tabular}{|c|c|c|c|c|c|c|c|c|c|}
\hline \multirow{2}{*}{ Variabel } & \multirow{2}{*}{ Kategori } & \multicolumn{2}{|c|}{ Over } & \multicolumn{2}{|c|}{ Obes } & \multirow{2}{*}{ p } & \multirow{2}{*}{ RP } & \multicolumn{2}{|c|}{ CI 95\% } \\
\hline & & $\mathbf{n}$ & $\%$ & $\mathbf{n}$ & $\%$ & & & Min & Maks \\
\hline Perilaku & Tidak sehat & 25 & 89,3 & 27 & 49,1 & $0,00^{*}$ & 0,12 & 0,31 & 0,43 \\
\hline Makan & Sehat & 3 & 10,7 & 28 & 50,9 & & & & \\
\hline
\end{tabular}

$R P=$ rasio prevalensi 
Tabel 3. Hubungan variabel luar dengan obesitas

\begin{tabular}{|c|c|c|c|c|c|c|c|c|}
\hline \multirow{2}{*}{ Variabel } & \multicolumn{2}{|c|}{ Over } & \multicolumn{2}{|c|}{ Obes } & \multirow[t]{2}{*}{$\mathbf{p}$} & \multirow[t]{2}{*}{ RP } & \multicolumn{2}{|c|}{ Cl $95 \%$} \\
\hline & $\mathbf{n}$ & $\%$ & $\mathbf{n}$ & $\%$ & & & Min & Maks \\
\hline \multicolumn{9}{|l|}{ Jenis kelamin } \\
\hline Laki-laki & 12 & 42,9 & 30 & 15,9 & 0,31 & 1,60 & 0,64 & 0,40 \\
\hline Perempuan & 16 & 57,1 & 25 & 54,5 & & & & \\
\hline \multicolumn{9}{|l|}{ Umur (tahun) } \\
\hline$<9$ & 38 & 69.1 & 21 & 75.0 & 0,57 & 0,75 & 0,26 & 0,20 \\
\hline$>9$ & 7 & 8.1 & 17 & 15.9 & & & & \\
\hline \multicolumn{9}{|l|}{ Total asupan energi } \\
\hline Total > AKG & 23 & 82,1 & 22 & 40,0 & 0,00 & 0,14 & 0,04 & 0,43 \\
\hline Cukup & 5 & 17,9 & 33 & 60.0 & & & & \\
\hline \multicolumn{9}{|c|}{ Asupan makanan di sekolah } \\
\hline$>50 \% A K G$ & 11 & 39,3 & 24 & 43,6 & 0,70 & 1,20 & 0,47 & 3,02 \\
\hline$<50 \%$ AKG & 17 & 60,7 & 31 & 56,4 & & & & \\
\hline \multicolumn{9}{|l|}{ Status gizi ibu } \\
\hline Obes & 10 & 35,7 & 36 & 65,6 & 0,01 & 3,41 & 1,31 & 8,84 \\
\hline Normal & 18 & 4,3 & 19 & 35,5 & & & & \\
\hline \multicolumn{9}{|l|}{ Status gizi bapak } \\
\hline Obes & 16 & 57,1 & 36 & 65,5 & 0,46 & 1,42 & 0,56 & 3,61 \\
\hline Normal & 12 & 42,9 & 19 & 35,5 & & & & \\
\hline \multicolumn{9}{|l|}{ Status gizi ibu/bapak } \\
\hline Obes & 14 & 28 & 36 & 72 & 0,42 & 0,68 & 0,24 & 1,93 \\
\hline Normal & 12 & 36,4 & 21 & 63,6 & & & & \\
\hline \multicolumn{9}{|l|}{ Pendapatan keluarga } \\
\hline$>\operatorname{Rp} 3.900 .000$ & 23 & 41,8 & 15 & 12,8 & 0,31 & 1,60 & 0,64 & 4,01 \\
\hline Cukup & 55 & 55,0 & 28 & 28.0 & & & & \\
\hline
\end{tabular}

variabel bebas dan variabel luar yang berhubungan dengan variabel terikat antara lain variabel perilaku makan, total asupan energi >AKG, status gizi ibu, dan status obesitas kedua orang tua subjek

Hasil analisis uji regresi logistik menunjukkan bahwa variabel total asupan energi yang melebihi AKG, merupakan variabel yang paling berpengaruh terhadap terjadinya obesitas pada subjek dibandingkan variabel lainnya $p<0,01 \operatorname{Eksp}(B)$ 12,46 , dengan kata lain terjadinya obesitas pada subjek lebih banyak 12 kali lebih besar terdapat pada subjek dengan asupan energi melebihi AKG.

\section{BAHASAN}

\section{Hubungan perilaku makan dengan obesitas anak}

Berdasarkan hasil uji tabulasi silang pada Tabel 2 diketahui bahwa ada hubungan yang signifikan antara perilaku makan dengan obesitas anak dengan kekuatan hubungan dan rasio prevalensi yang bersifat protektif. Subjek yang mempunyai perilaku makan sehat mempunyai peluang 8,3 kali untuk terhindar dari terjadinya obesitas dibandingkan dengan anak yang berperilaku makan tidak sehat.

Perilaku makan anak dapat dibentuk melalui pengalaman awalnya berdasarkan perilaku makan orang tuanya. Orang tua berperan untuk selalu memantau perkembangan anak baik berat badan maupun dalam hal memilih makanan. Makanan yang sehat dapat dicapai dengan memperbanyak menu makanan yang mengandung serat seperti sayur dan buah yang banyak dikenal sebagai peluruh lemak. Berdasarkan penelitian Nuraeni et al (10) pada anak SD di Kota Yogyakarta dan Bantul, anak yang konsumsi sayur dan buahnya jarang ( $<7 \mathrm{kali} /$ minggu) berisiko lebih besar manjadi obes. Bila ditinjau dari pemilihan makanan, alasan seseorang mengalami kelebihan berat badan karena banyak faktor yang mempengaruhi, di antaranya perilaku makan. Menurut Wardle perilaku 
Tabel 4. Hasil analisisis regresi logistik

\begin{tabular}{lcccccc}
\hline \multicolumn{1}{c}{ Variabel } & \multirow{2}{*}{ B } & \multirow{2}{*}{ SE } & p & \multirow{2}{*}{ Exp(B) } & \multicolumn{2}{c}{$\mathbf{9 5 \%}$ Cl } \\
\cline { 6 - 7 } & & & & & Min & Maks \\
\hline Total asupan energi & 2,52 & 0.71 & 0,00 & 12,46 & 3.09 & 50.24 \\
Perilaku makan & 2,45 & 0,77 & 0,00 & 11,59 & 2,53 & 53,11 \\
\hline
\end{tabular}

makan berhubungan dengan obesitas (11). Fakta menunjukkan semakin tinggi umur anak, semakin berkurang anak obesitas, tapi secara statistik tidak berhubungan dengan umur. Kebanyakan anak mulai merasa malu bila ketahuan banyak makan, ini nampak pada saat wawancara total asupan kurang, tetapi sebagian anak yang didampingi ibunya mengakui bahwa anaknya banyak makan (porsi besar dan sering).

Tidak dapat dipungkiri anak obes selalu berkeinginan untuk makan. Hal ini sesuai dengan hasil penelitian Webber menemukan bahwa anak dengan berat badan lebih memiliki responsivitas yang tinggi terhadap sinyal aroma masakan dan makan lebih cepat selama waktu makan, dibanding anak yang berat badannya normal (12). Kelemahan dari penelitian ini tidak melihat penyebab turunnya berat badan seperti yang dikatakan sebelumnya, semakin tinggi umur semakin berkurang anak obesitas. Faktor lain yang tidak diteliti seperti: aktivitas fisik, psikologi dan lingkungan keluarga, dan melihat anak obesitas yang diteliti di SD Kuncup ini sudah terkondisi jauh sebelum masuk sekolah atau belum, sehingga anak tetap memiliki berat badan lebih meskipun sudah melakukan perilaku makan yang sehat. Menurut Syarif, perilaku makan anak obes mulai terkondisi dan terlatih sejak bulan-bulan pertama kehidupan bayi yaitu dengan pemberian susu botol yang diberikan dalam jumlah berlebihan dari kebutuhannya dan dapat berlanjut ke masa usia sekolah (13). Azwar menegaskan bahwa lingkungan memiliki kekuatan lebih besar daripada karakteristik individu. Perubahan perilaku pada anak masih dipengaruhi oleh kelompok maupun individu atau orang tuanya (14).

\section{Hubungan variabel luar dengan obesitas}

Berdasar hasil penelitian pada Tabel 3 menunjukkan bahwa tidak ada hubungan yang signifikan antara asupan energi subjek yang dikonsumsi di sekolah dengan kejadian obesitas. Asupan energi subjek dalam penelitian ini merupakan asupan energi selama di sekolah dan di luar sekolah, termasuk di rumah dan tempat makan lain. Hal itu berhubungan sangat signifikan dengan terjadinya obesitas yang bersifat protektif. Anak yang mempunyai asupan energi sesuai kebutuhan tubuh (cukup) akan terhindar dari obesitas sebesar 7,1 kali lebih besar dibandingkan dengan anak yang mempunyai asupan energi lebih besar dari \% AKG. Asupan energi yang cukup diperlukan tubuh agar dapat melaksanakan kegiatannya sehari-hari. Asupan makanan dan aktivitas fisik memegang peran penting terjadinya obesitas pada seseorang. Kedua aspek ini mengalami banyak perubahan pada masyarakat seiring dengan semakin meningkatnya gaya hidup sedentary. Menurut Arisman, obesitas merupakan dampak ketidakseimbangan asupan yang jauh melampaui keluaran energi dalam jangka waktu tertentu (4). Hal ini sesuai hasil penelitian Pampang yaitu anak yang obes cenderung mengonsumsi energi lebih tinggi 6,9 kali lebih besar dibanding anak yang tidak obes (6).

Hasil analisis zat gizi dalam penelitian ini menunjukkan bahwa asupan energi sebagian besar diperoleh dari kebiasaan makan di luar rumah dalam bentuk camilan, snack, dan makanan lain yang terdapat di warung makanan. Hasil observasi yang dilakukan, kebanyakan anak memilih makanan maupun minuman yang manis-manis. Hasil penelitian ini sesuai dengan teori yang diambil dari Webber et al bahwa hubungan antara keinginan minum, paling tidak dalam lingkungan dimana banyak minuman yang kaya energi berhubungan dengan obesitas (12). Penelitian ini juga didukung oleh Devi bahwa perilaku makan dan status gizi anak menunjukkan hubungan yang signifikan dan lebih lanjut berpendapat bahwa gizi merupakan salah satu faktor menentukan kualitas SDM yang berkualitas (8). Pemenuhan kebutuhan akan 
pangan sangat ditentukan oleh kebiasaan atau perilaku makan seseorang yaitu dengan cara menyediakan makanan yang bermutu tinggi guna memenuhi kebutuhan selama mengikuti pelajaran di sekolah karena kegiatan di sekolah menyita waktu terbesar dari aktivitas sehari-hari, termasuk aktivitas makan.

Hasil analisis hubungan antara status gizi ibu (genetik) dengan obesitas anak, menunjukkan adanya hubungan yang signifikan dengan terjadinya obesitas pada anak $p<0,05 R P=3,4$. Demikian pula dengan status obesitas pada kedua orang tua subjek (bapak dan ibu) salah satu di antaranya atau keduanya obes mempunyai hubungan yang signifikan dengan terjadinya obesitas pada anak $p<0,05 R P=2,91$. Hal ini sesuai dengan pendapat Barasi bahwa beberapa penyakit keturunan sangat jelas terkait dengan obesitas. Kegemukan dapat diturunkan dari generasi sebelumnya pada generasi berikutnya di dalam sebuah keluarga. Oleh karena itu, seringkali dijumpai orang tua yang gemuk cenderung memiliki anak-anak yang gemuk pula (15). Pendapat serupa juga disampaikan Asdie yang mengatakan bahwa seorang anak mempunyai kemungkinan $40 \%$ menjadi obes apabila ia salah satu orang tuanya obes. Kemungkinan besar lagi $80 \%$ menjadi obes jika kedua orang tuanya obes (16).

\section{Analisis multivariat hubungan beberapa variabel dengan obesitas}

Hasil analisis multivariat menunjukkan bahwa variabel luar (asupan energi total >AKG) merupakan variabel yang paling berpengaruh terhadap kejadian obesitas pada subjek dibandingkan variabel lainnya. Hal ini sesuai dengan penelitian Pampang, yaitu anak yang obes cenderung mengonsumsi energi lebih tinggi 6,9 kali lebih besar dibanding anak yang tidak obes (6). Demikian juga menurut Elvira, kegemukan atau obesitas adalah kelainan atau penyakit yang ditandai dengan adanya akumulasi atau penimbunan jaringan lemak di bawah kulit yang berlebihan dan terdapat di seluruh tubuh. Adanya perubahan gaya hidup yang menjurus pada perubahan pola makan/konsumsi masyarakat yang merujuk pada pola makan tinggi kalori, tinggi lemak dan kolesterol terutama terhadap penawaran makanan siap saji (fast food) yang berdampak meningkatkan resiko obesitas (17).

\section{KESIMPULAN DAN SARAN}

Ada hubungan yang signifikan antara perilaku makan dengan obesitas anak. Kekuatan hubungan dan rasio prevalensi bersifat protektif, yaitu subjek yang mempunyai perilaku makan sehat mempunyai peluang 8,3 kali untuk terhindar dari terjadinya obesitas dibandingkan dengan anak yang berperilaku makan tidak sehat.

Perlu diupayakan pemberian makanan ringan atau makan siang yang dilakukan di lingkungan sekolah. Hal ini dilakukan untuk mencegah agar anak tidak sembarang jajan. Untuk mengurangi paparan anak sekolah terhadap makanan jajanan yang tidak sehat dan tidak aman, perlu dilakukan usaha promosi keamanan pangan baik kepada pihak sekolah, guru, orang tua, murid, serta pedagang. Pentingnya penyuluhan tentang makanan sehat agar anak sekolah dapat menentukan pilihan makanan yang akan dikonsumsi. Diperlukan kerjasama antara petugas gizi dan guru UKS untuk selalu memantau BB (berat badan) anak setiap bulannya. Penelitian ini perlu dilanjutkan dengan menggunakan variabel lingkungan keluarga sebagai variabel utama karena lingkungan salah satu faktor yang berperan dan memiliki kekuatan yang besar dalam menentukan perilaku makan anak, bahkan kekuatannya lebih besar dari pada karakteristik individu.

\section{RUJUKAN}

1. Supari SF. Obesitas dan kurang aktivitas fisik menyumbang 30\% kanker. Dalam: Seminar sehari dan talk show bagi anak-anak SD dan SMP: 2009; Departemen Kesehatan RI. Jakarta: Depkes RI; 2009.

2. Depkes RI. Laporan Hasil Riset Kesehatan Dasar (Riskesdas) [serial online] 2007 [Disitasi Juni 2009]. Tersedia dalam: http.www.kesehatan. kebumenkab.go.id/data/lapriskesdas. pdf>.

3. Maffeis C, Provera S, Fillippi L, Sidotti G, Scenna S, Pinelli Ltatto L. Distribution of food 
intake as a risk faktor for childhood obesity. Int J Obes 2000;24:75-80.

4. Arisman MB. Obesitas, diabetes milletus, dan dislipidemia: konsep, teori dan penanganan aplikatif. seri buku ajar ilmu gizi. Jakarta:EGC;2010.

5. Huriyati E. Studi kohort prevalensi obesitas siswa-siswi SLTP Kota Yogyakarta Jurnal Gizi Klinik Indonesia 2006.3(1):1-5.

6. Pampang E. Asupan energi, aktivitas fisik, persepsi orangtua dan obesitas siswa SMP di Kota Yogyakarta. Yogyakarta:Universitas Gadjah Mada;2007.

7. Judarwanto W. Perilaku makan anak sekolah. Picky Caters Clinic (Klinik Khusus Kesulitan Makan Pada Anak [serial online] [Disitasi 3 Desember 2009]. Tersedia dalam: http://www.gizi. net/makalah/perilaku/makan/anak/sekolah.pdf

8. Devi M. Tingkat pendidikan ibu, hubungannya dengan perilaku makan dan status gizi siswa sekolah. Bogor: Institut Pertanian Bogor.

9. Soegih R,Wiramihardja K. Obesitas permasalahan dan terapi Praktis. Jakarta: Sagung Seto; 2009.
10. Nuraeni I, Hadi H, Paratmanitya Y. Perbedaan konsumsi buah dan sayur pada anak sekolah dasar yang obes dan tidak obes di Kota Yogyakarta dan Kabupaten Bantul. Jurnal Gizi dan Dietetik Indonesia 2013; I(2): 81-92.

11. Wardle J. Eating behaviour and obesity. Int $\mathrm{J}$ Obes 2008:5-15.

12. Webber L, Wardel J, Hill C, Saxon J, Jaarsveld. Eating behaviour and weight in children. Int $\mathrm{J}$ Obes 2008;33:21-8.

13. Sjarif DR. Obesitas pada anak dan permasalahannya, Hot topics inpedia. Jakarta:PKB IKA XLV;2003, p. 219-22.

14. Azwar S. Sikap manusia; teori dan pengukuran. Jakarta:Pustaka Pelajar; 2005.

15. Barasi. Nutritional at a glance. Jakarta: Erlangga; 2007.

16. Asdie AH. Mencegah obesitas sejak dini: pikiran rakyat. Cyber Media 2007 [serial online] [diakses 4 oktober 2009]. Tersedia dalam: http:// www.Pikiran-rakyat.com.

17. Elvira SD. Penanganan psikologik pada obesitas. Cermin dunia kedokteran 2007;34(6):296-30. 